\title{
Diversity and structure of a bacterial community in grassland soils disturbed by sheep grazing, in the Loess Plateau of northwestern China
}

\author{
Y.N. Gou' ${ }^{1}$ Z.B. Nan ${ }^{1}$ and F.J. Hou ${ }^{1}$ \\ ${ }^{1}$ Key Laboratory of Grassland Agro-Ecosystems, College of Pastoral Agriculture \\ Science and Technology, Lanzhou University, Lanzhou, Gansu, China \\ Corresponding author: Z.B. Nan \\ E-mail: zhibiao@Izu.edu.cn
}

Genet. Mol. Res. 14 (4): 16987-16999 (2015)

Received August 24, 2015

Accepted October 11, 2015

Published December 15, 2015

DOI http://dx.doi.org/10.4238/2015.December.15.5

\begin{abstract}
The relationship between disturbance, biodiversity, and ecosystem function has been a hot topic recently in international ecological research, and a universally applicable model remains elusive. In this study, we assessed the diversity and structure of a bacterial community in grassland soils along a disturbance gradient due to sheep grazing. Bacteria were identified based on 16S rDNA gene libraries prepared from a 12-year field experiment that included four grazing, intensity treatments: no grazing, light grazing, moderate grazing and heavy grazing in the Loess Plateau of northwestern China. We found that diversity indices of bacterial $16 \mathrm{~S}$ rDNA increased with grazing intensity, suggesting that disturbance led to higher bacterial diversity. The bacterial community structure, measured as species composition, was also affected by grazing. In addition, the change in soil bacterial community composition was maximum under heavy grazing, based on the Sorensen similarity index. Overall, the relationship between disturbance and bacterial diversity is complex, therefore, more studies are required to determine the possibility of using microbial diversity
\end{abstract}


as an indicator of ecosystem stability.

Key words: Grassland soil; Bacterial diversity; 16S rDNA clone library; Grazing

\section{INTRODUCTION}

Recently, the relationship between environmental disturbance, biodiversity, and ecosystem function has received much international attention from the research community, yet a universally applicable model has not been achieved (Death and Barquín, 2012). Links between disturbances and biodiversity changes are complicated. Hughes (2012) demonstrated causation in the disturbance-diversity relationship and reviewed several possible proposed models: the intermediate disturbance hypothesis (IDH) (Connell, 1978), the positive relationship model, the negative relationship model, the unimodal relationship model with a peak at intermediate values, the unimodal relationship model peaking at either extreme, and no significant relationship model (Mackey and Currie, 2001; Hughes et al., 2007). The response of bacterial diversity to ecosystem changes has not been systematically addressed with multitudinous research subjects, although many studies have demonstrated that species diversity is closely related to ecosystem function and biogeochemical processes (Schwartz et al., 2000).

Microbes are abundant and ubiquitous in terrestrial ecosystems. For example, the diversity of mycorrhizal fungi affects plant diversity and ecosystem stability and productivity (van der Heijden et al., 1998), while microbial diversity in general influences the ability of ecosystems to withstand stress and disturbances (Sugden, 2000; Johnsen et al., 2001). While soil microbial diversity incorporates species, structural, genetic and functional diversity, genetic diversity is particularly important (Lynch et al., 2004) and has played an increasing role in studies of diversity with the identification of molecular markers (Kozdroj and van Elsas, 2001).

The study area on the Loess Plateau in China occurs in a typical transitional zone between cropping and pastoral production. Grazing of grassland is an important livestock husbandry activity and eco-safeguard, accounting for the largest proportion of the region's land areas (Bilotta et al., 2007). Many studies have assessed the grassland degeneration of livestock herds by measuring soil microbes, including carbon and nitrogen levels in the microbial biomass, microbial abundance, and microbial community structure. Effects on microbial diversity are less understood and changes in diversity following grazing are thought to be quite complex (Belay-Tedla et al., 2009; Grigulis et al., 2013). Some studies have observed significant differences in microbial biomass and bacterial community structure between grazing and non-grazing lands (Liu et al., 2012; Oates et al., 2012; Yang et al., 2013) yet microbial diversity had not apparently changed. However, Zhou et al. (2010) found that the number of microbe species reached a maximum in moderately grazed plots, a result that supports the IDH. Thus, understanding the effects of grazing intensity on soil microbial diversity is essential for understanding how grazing influences grassland microbe communities.

Soil bacteria are highly abundant and very diverse so they are difficult to monitor by traditional survey methods. As an alternative to these methods, we used 16S rDNA, which is an effective tool for the investigation of bacterial genetic diversity and has been successfully used in various environments. In order to elucidate the potential relationship between soil bacterial diversity and grazing density, we studied bacterial genetic diversity along a gradient of grazing intensity using a $16 \mathrm{~S}$ rDNA clone library. 


\section{MATERIAL AND METHODS}

\section{Study site and sampling}

The study site is located in Huan County, Gansu province, LongDong on the Loess Plateau of China $\left(37.12^{\circ} \mathrm{N}, 106.82^{\circ} \mathrm{E}\right)$, near the border of Shanxi, Gansu and the Ningxia autonomous region. A longterm sheep grazing experiment was established in 2001. Rotational grazing was permitted for 3 months (15 June to 15 September 2012), with 30 days of grazing per rotation and 3 total grazing rotations. Top soil $(0-10 \mathrm{~cm})$ samples were collected from twelve experimental plots (50 x $100 \mathrm{~m}$ each) on 15 May 2012, including three replicates from each of four treatments: no grazing (CK, 0.0 sheep/ha), light grazing (LG, 2.7 sheep/ha), moderate grazing (MG, 5.3 sheep/ha) and heavy grazing (HG, 8.7 sheep/ha).

\section{DNA extraction and preparation for 16S rDNA gene libraries}

Microbial DNA was extracted from soil samples using the UltraClean Soil DNA isolation kit (MoBio Laboratories, Carlsbad, CAUSA) according to manufacturer instructions and then stored at $-20^{\circ} \mathrm{C}$. The16S rDNA genes were amplified from each of the 12 samples using the universal forward primer $27 \mathrm{f}$ (5'-AGAGTTTGATCCTGGCTCAG-3') and the reverse primer 1492r (5'-TACGGCTACCTTACGACTT-3'). A reaction mixture $(50 \mu \mathrm{L})$ contained $5 \mu \mathrm{L}$ 10X Taq buffer, $1.5 \mathrm{mM} \mathrm{MgCl}, 1 \mu \mathrm{L} 10 \mathrm{X}$ dNTP mix, $0.2 \mu \mathrm{M}$ of each primer, $0.5 \mu \mathrm{L}$ Taq DNA polymerase, $1 \mu \mathrm{L}$ template DNA, and sterile Milli-Q water (Sangon Biotech, Shanghai, China). Thermal cycling included an initial denaturation step at $94^{\circ} \mathrm{C}$ for 5 min and 30 cycles of denaturation at $94^{\circ} \mathrm{C}$ for $30 \mathrm{~s}$, annealing for $30 \mathrm{~s}$ at $52^{\circ} \mathrm{C}$, and extension at $72^{\circ} \mathrm{C}$ for 2 min. Cycling was completed with a final elongation step at $72^{\circ} \mathrm{C}$ for $10 \mathrm{~min}$. The PCR products were purified by TaKaRa Agarose Gel DNA Purificati on Kit (Ver. 2.0, Dalian, China) and the three duplicate products from the same treatment were combined as a single sample for cloning.

\section{Cloning}

After PCR, the products were cloned using the pUCm-T vector system according to manufacturer instructions. Clones were selected randomly (recombinant clones were distinguished by their white color) from the LB-agar plates with the three repeats of each sample. These plasmidharboring clones were transferred with a sterile toothpick into $10 \mu \mathrm{L}$ sterile water and amplified with M13 pUCm-T-specific primers to confirm correct insertions (approximately $1700 \mathrm{bp}$ ). Following this, 100 clones of each soil sample were sent for sequencing (Sangon Biotech Co. Ltd., Shanghai, China) with the bacterial universal primers $16 \mathrm{~S}-27 \mathrm{f}$ and $1492 \mathrm{r}$.

\section{Sequencing analysis and phylogenetic analysis}

The 16S rDNA sequences were trimmed to 1400-1600bp and discard chimeric sequences: i). removed vector and primer sequences using DNAman v.6.0. ii) checked and deleted the chimeric sequence by Check_Chimera (http://comp-bio.anu.edu.au/bellerophon/bellerophon.pl). The edited sequences were submitted to GenBank with accession numbers KJ540628 to KJ540879 (Table S1). The operational taxonomic unit (OTU) sequences with more than $97 \%$ similarity were considered as members of the same OTU using the Mothur software. Rarefaction analysis was conducted to determine the number of unique sequences as a proportion of the estimated total diversity. The rarefaction curves were constructed using EstimateS 8.0 (http://viceroy.eeb. uconn.edu/estimates). According to the software manual, the clone coverage was calculated 
using the formula $\mathrm{C}=(1-\mathrm{n} / \mathrm{N}) \times 100 \%$, where $\mathrm{n}$ is the number of phylotypes appearing only once in a library and $\mathrm{N}$ is the library size. Then, the representative sequences of each OTU were analyzed and compared to sequences within the National Center for Biotechnology Information (NCBI) database (http://www.ncbi.nlm.nih.gov/) using the Basic Local Alignment Search Tool (BLAST). In addition, each phylogenetic classification was inferred by submitting the sequences to the Classifier from the Ribosomal Database Project (RDP) release 10.0 (http://rdp.cme.msu. edu/classifier). Phylogenetic analysis was performed using MEGA version 4.5 and the neighborjoining tree was constructed using the Poisson correction model with a bootstrap value of 1000 .

\section{RESULTS}

\section{Comparison between the bacterial 16S rDNA clone libraries}

Rarefaction curves for clone libraries from samples of the OTUs from the four treatments (CK, LG, MG, and HG) were determined with a similarity cutoff value of $97 \%$. Rarefaction analysis to estimate the degree of coverage of the natural microbial diversity from the bacterial clone libraries from the four treatments is shown in Figure 1.

Of the four clone libraries, the shape of the curve for $\mathrm{CK}$ had the closest fit to the steady trend, followed by the other three treatments in the order LG, MG and HG. The coverage of the CK, LG, MG and HG treatments was $61,59,49$ and $41 \%$, respectively (Table 1 ). It indicated that the clone library can reflect the diversity of soil bacteria.

Table 1. Diversity indices for the bacterial communities as represented by the $16 \mathrm{~S}$ rRNA gene libraries ${ }^{\mathrm{a}}$.

\begin{tabular}{lccccccc}
\hline Index & $\mathrm{N}^{\mathrm{b}}$ & $\mathrm{S}^{\mathrm{c}}$ & Coverage $^{\mathrm{d}}(\%)$ & Shannon $^{\mathrm{e}}$ & Simpson's $^{\mathrm{f}}$ & Margalef Richness $^{\mathrm{g}}$ & Evenness $^{\mathrm{h}}$ \\
\hline CK & 100 & 56 & 61 & 3.76 & 0.98 & 11.94 & 0.93 \\
LG & 100 & 59 & 56 & 3.84 & 0.98 & 12.59 & 0.94 \\
MG & 102 & 66 & 49 & 3.93 & 0.98 & 14.05 & 0.94 \\
HG & 102 & 72 & 41 & 4.11 & 0.98 & 15.35 & 0.96 \\
\hline
\end{tabular}

${ }^{a}$ Calculations were based on OTUs formed at an evolutionary distance of $\leq 0.03$ (or about $97 \%$ sequence similarity). ${ }^{b} \mathrm{~N}$ is defined as the number of sequences. ${ }^{\mathrm{S}} \mathrm{S}$ is defined as the number of OTUs. ${ }^{\mathrm{d}}$ Coverage $(\mathrm{C})=1-\mathrm{ni} / \mathrm{N}$. eShannon index $(\mathrm{H})=-\sum \mathrm{Pi}{ }^{*} \log 2 \mathrm{Pi}$, $\mathrm{Pi}=\mathrm{ni} / \mathrm{N}$. 'Simpson's index (D) = $1-\sum[(\mathrm{ni}(\mathrm{ni}-1) / \mathrm{N}(\mathrm{N}-1)]$. 9Margalef Richness = (S-1) / In N. hEvenness $=\mathrm{H} / \mathrm{Hmax}, \mathrm{Hmax}=$ InS. Treatments: control without grazing (CK), light grazing (LG), moderate grazing (MG), and heavy grazing (HG).

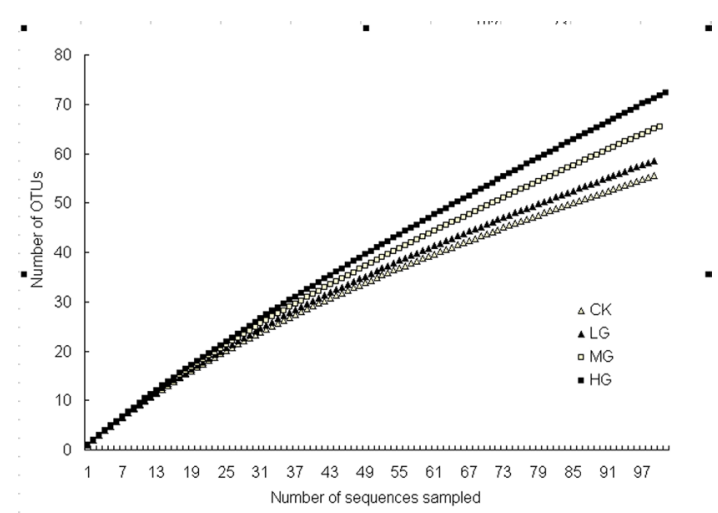

Figure 1. Rarefaction analysis of the $16 \mathrm{~S}$ rRNA clones obtained from grassland soils with different grazing density treatments using the software Estimates 8.0. CK: control without grazing, LG: light grazing, MG: moderate grazing, HG: heavy grazing. 


\section{Diversity indices}

Estimates of bacterial 16S rDNA diversity in the four treatment conditions, based on the diversity indices, are shown in Table 1. The Shannon index, Simpson index, and Margalef richness all increased as grazing became more intense, while evenness was higher for MG compared to CK, but lower than LG and HG. The results suggest that the diversity of bacterial 16S rDNA was greater with increasing grazing intensity.

\section{Phylogenic groups represented in clone libraries}

In the CK treatment, the results of 100 matched sequences showed that the similarity rate of sequences ranged from 82 to $100 \%$, and while 12 sequences had a similarity rate $\geq 97 \%$, most sequences (88\%) belonged to unknown genotypes (Stackebrandt and Goebel, 1994). The phylogeny of the $16 \mathrm{~S}$ rDNA sequences from 56 OTUs from the CK treatment, along with reference sequences from GenBank, is shown in Figure 2. All detected 16S rDNA sequences belonged to 10 bacterial phyla: Proteobacteria, Acidobacteria, Actinobacteria, Bacteroidetes, Gemmatimonadetes, Nitrospirae, Verrucomicrobia, Planctomycetes, OD1, and TM7.

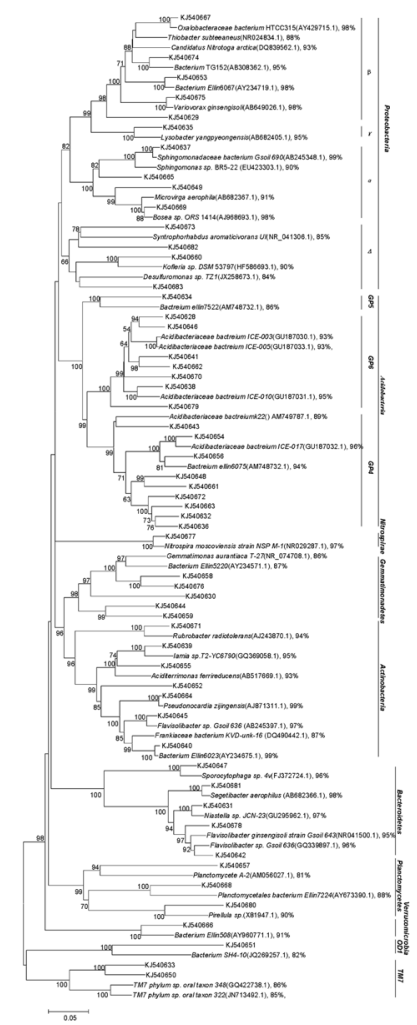

Figure 2. Phylogenic tree of bacterial $16 \mathrm{~S}$ rRNA sequences. Bootstrap values (>50\%) are indicated at branch points. The phylogenetic tree showing the affiliation of the representative bacterial 16S rRNA gene sequences retrieved from this study with control without grazing (CK) treatment and GenBank accession numbers. Sequences from this study are shown by GenBank accession number. 
In the LG treatment, the similarity rate of 100 sequences was 83 to $99 \%$, and while 9 sequences had a similarity rate $\geq 97 \%$, most sequences $(91 \%)$ were of unknown genotypes. The phylogeny of $16 \mathrm{~S}$ rDNA sequences from 59 OTUs from the LG treatment, along with reference sequences from GenBank, is shown in Figure 3. All the detected 16SrDNA sequences were grouped into 13 bacterial phyla: Proteobacteria, Acidobacteria, Actinobacteria, Bacteroidetes, Gemmatimonadetes, Nitrospirae, Verrucomicrobia, Planctomycetes, Chloroflexi, Cyanobacteria, Armatimonadetes, Firmicutes, and unclassified bacteria.

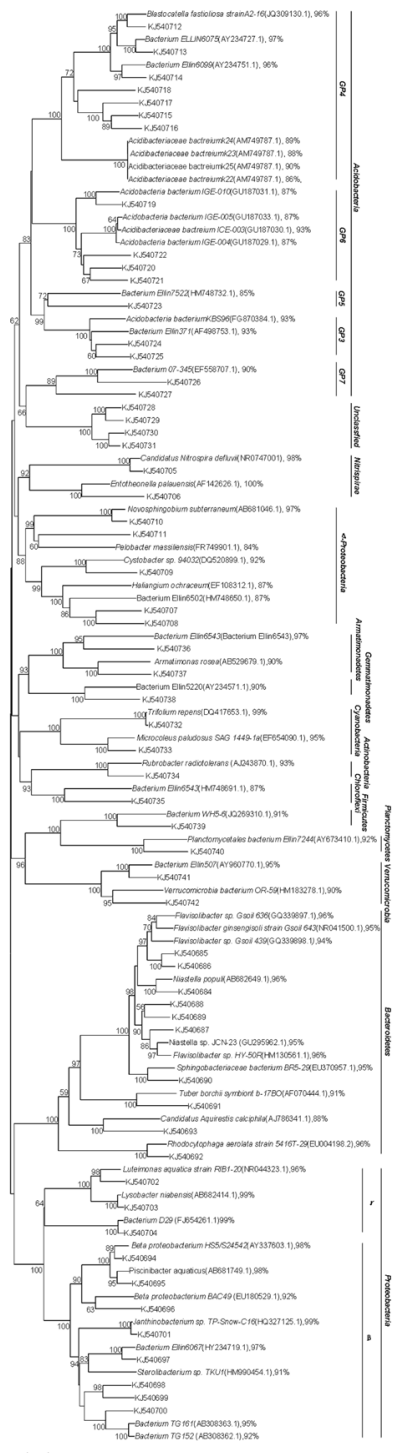

Figure 3. Phylogenetic tree of representative bacterial 16S rRNA sequences from light grazing (LG) treatment and their affiliation with GenBank accession numbers. Bootstrap values $(>50 \%)$ are indicated at branch points. Sequences from this study are shown by GenBank accession number. 
In the MG treatment, the similarity rate of 102 sequences was 81 to $99 \%$, and while 11 sequences had a similarity rate $\geq 97 \%$, most sequences $(89 \%)$ were of unknown genotypes. The phylogeny of $16 \mathrm{~S}$ rDNA sequences from 66 OTUs from the MG treatment, along with reference sequences from GenBank, is shown in Figure 4. All the detected 16S rDNA sequences were grouped into 12 bacterial phyla: Proteobacteria, Acidobacteria, Actinobacteria, Bacteroidetes, Gemmatimonadetes, Nitrospirae, Verrucomicrobia, Planctomycetes, Chloroflexi, Armatimonadetes, and unclassified bacteria.

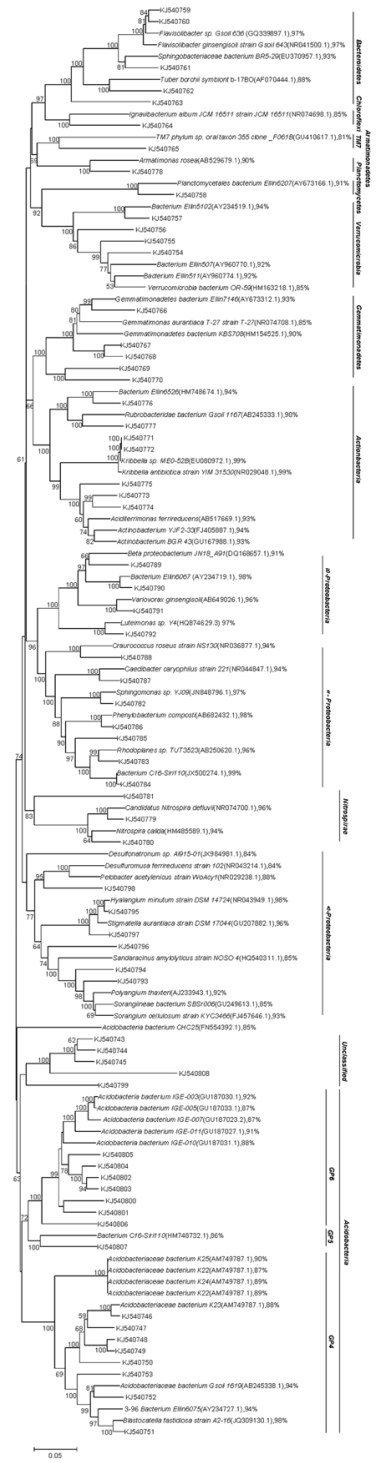

Figure 4. Phylogenetic tree of representative bacterial $16 \mathrm{~S}$ rRNA sequences from moderate grazing (MG) treatment and their affiliation with GenBank accession numbers. Bootstrap values (>50\%) are indicated at branch points. Sequences from this study are shown by GenBank accession number. 
In the HG treatment, the similarity rate of 102 sequences was 83 to $99 \%$, of which 8 sequences had a similarity rate shown in Figure 2. $92 \%$ of the sequences were of unknown genotypes. The phylogeny of $16 \mathrm{~S}$ rDNA sequences from 72 OTUs from the HG treatment, along with reference sequences from GenBank, is shown in Figure 5. All the detected 16S rDNA sequences were grouped into 12 bacterial phyla: Proteobacteria, Acidobacteria, Actinobacteria, Bacteroidetes, Gemmatimonadetes, Nitrospirae, Verrucomicrobia, Planctomycetes, Chloroflexi, TM7, and unclassified bacteria.

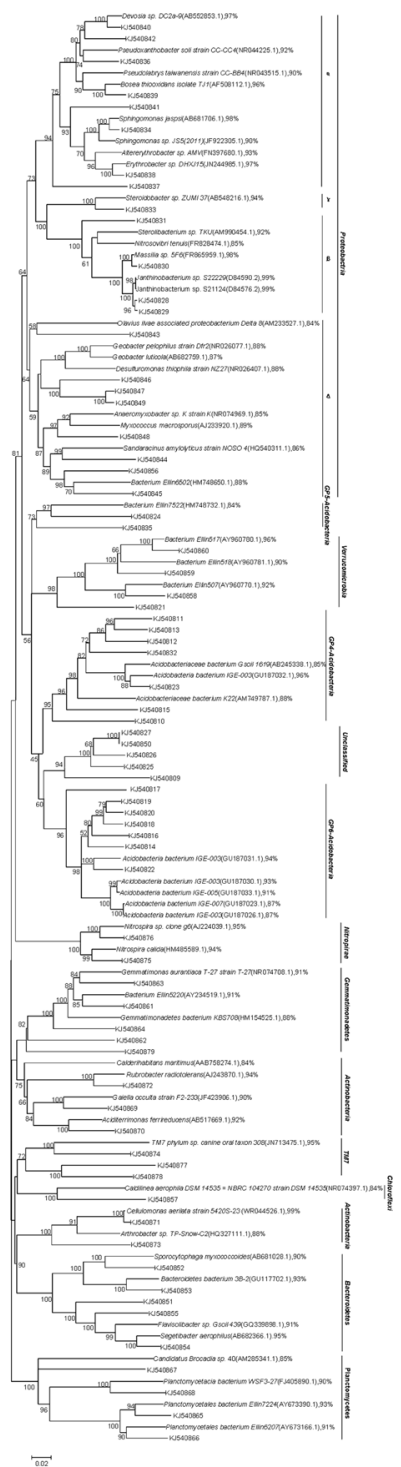

Figure 5. Phylogenetic tree of representative bacterial $16 \mathrm{~S}$ rRNA sequences from heavy grazing $(\mathrm{HG})$ treatment and their affiliation with GenBank accession numbers. Bootstrap values $(>50 \%)$ are indicated at branch points. Sequences from this study are shown by GenBank accession number. 


\section{Structure of bacterial communities}

The main species of bacteria identified by RDP and phylogenetic analysis in each treatment are summarized in Table 2. In the treatment with no grazing (CK), the predominant bacteria were Proteobacteria and Acidobacteria, which represented 20 and $48 \%$ of the total clones, respectively. The Proteobacteria had 4 classes including $\beta$-Proteobacteria ( $7 \%$ of clones), y-Proteobacteria $(1 \%$ of clones), $\alpha$-Proteobacteria ( $6 \%$ of clones) and $\Delta$-Proteobacteria ( $6 \%$ of clones). The Acidobacteria had 3 classes including Gp4 (28\% of clones), Gp5 (1\% of clones) and Gp6 (19\% of clones).

In the LG treatment, the predominant bacteria were Proteobacteria, Acidobacteria and Bacteroidetes, which represented 20,42 and $16 \%$ of the total number of clones, respectively. The Proteobacteria had 3 classes including $\beta$ - Proteobacteria (10\% of clones), y-Proteobacteria ( $3 \%$ of clones) and $\Delta$-Proteobacteria (6\% of clones). The Acidobacteria had 5 classes including Gp3 (4\% of clones), Gp4 (22\% of clones), Gp5 (1\% of clones), Gp6 (13\% of clones), and GP7 ( $2 \%$ of clones).

In the MG treatment, the predominant bacteria were Proteobacteria and Acidobacteria, which represented 17 and $41 \%$ of the total number of clones, respectively. The Proteobacteria had 3 classes including $\beta$-Proteobacteria ( $4 \%$ of clones), $\alpha$-Proteobacteria ( $7 \%$ of clones) and $\Delta$-Proteobacteria ( $6 \%$ of clones). The Acidobacteria had 3 classes including Gp4 (23\% of clones), Gp5 (1\% of clones) and Gp6 (17\% of clones).

In the HG treatment, the predominant bacteria were Proteobacteria and Acidobacteria, which consisted of 25 and $36 \%$ of the total number of clones, respectively. The Proteobacteria had 4 classes including $\beta$ - Proteobacteria ( $6 \%$ of clones), $\gamma$ - Proteobacteria ( $2 \%$ of clones), a-Proteobacteria ( $9 \%$ of clones) and $\Delta$-Proteobacteria ( $8 \%$ of clones). The Acidobacteria had 3 classes including Gp4 (18\% of clones), Gp5 (2\% of clones) and Gp6 (9\% of clones).

This observation showed that eight bacterial phyla were common to all four treatments, while seven bacterial phyla were distributed differently among the treatments. The dominant bacteria were Proteobacteria and Acidobacteria, which were present in different relative proportions in each treatment. The LG treatment had one additional phylum, Bacteroidetes. The number of bacterial phyla present in grazing treatments was more than those present in the control samples, and an unclassified phylum was detected in all grazing treatments. In the LG treatment, the proportion of Actinobacteria (1\%) and Gemmatimonadetes (1\%) were the least among all treatments (6-8\%). Nitrospirae was most common in the MG treatment (7\%) compared to the other treatments $(1-2 \%)$. Five phyla of bacteria were present in the grazed areas but were not detected in the CK treatment: Planctomycetes, Chloroflexi, Cyanobacteria, Armatimonadetes and unclassified bacteria. This demonstrates that grazing can alter the composition and structure of the soil bacterial community.

\section{Composition of bacterial communities}

The Sorensen similarity index was used to characterize the similarity of $16 \mathrm{~S}$ rDNA library compositions between all pairwise treatment comparisons and ranged from 15 to $28 \%$ (Table 3 ). A relatively high Sorensen similarity index was found between the LG and MG samples, indicating that they had very similar $16 \mathrm{~S}$ rDNA clone library compositions. The HG treatment had lower similarity values of 17,15 and $25 \%$ compared to the CK, LG MG treatments, respectively, suggesting that its library compositions were distinctly different from other libraries. These results show that heavily grazed land experienced the greatest change in composition of the soil bacterial community. 
Table 2. Percentages of bacterial phyla in the soil of four different grazing treatments.

\begin{tabular}{lcccc}
\hline & CK (\%) & LG (\%) & MG (\%) & HG (\%) \\
\hline Acidobacteria & 48 & 42 & 41 & 36 \\
GP3 & 0 & 4 & 0 & 0 \\
GP4 & 28 & 22 & 23 & 18 \\
GP5 & 1 & 1 & 1 & 2 \\
GP6 & 19 & 13 & 17 & 16 \\
GP7 & 0 & 2 & 0 & 0 \\
Proteobacteria & 20 & 20 & 17 & 25 \\
$\beta$ & 7 & 10 & 4 & 6 \\
Y & 1 & 3 & 0 & 2 \\
$\alpha$ & 6 & 0 & 7 & 9 \\
$\Delta$ & 6 & 6 & 6 & 8 \\
Bacteroidetes & 8 & 16 & 8 & 5 \\
Actinobacteria & 8 & 1 & 8 & 7 \\
Gemmatimonadetes & 7 & 1 & 7 & 2 \\
Nitrospirae & 1 & 1 & 1 & 4 \\
Planctomycetes & 3 & 4 & 4 & 5 \\
Verrucomicrobia & 1 & 0 & 0 & 0 \\
OD1 & 2 & 0 & 1 & 2 \\
TM7 & 2 & 1 & 0 & 0 \\
Firmicutes & 0 & 3 & 1 & 2 \\
Cyanobacteria & 0 & 2 & 1 & 0 \\
Armatimnadetes & 0 & 1 & 8 & 6 \\
Chloroflexi & 0 & 7 & 0 & 0 \\
Unclassified Bacteria & 0 & 1 & 0 & 2 \\
\hline
\end{tabular}

Treatments: control without grazing (CK), light grazing (LG), moderate grazing (MG), and heavy grazing (HG)

Table 3. Sorensen similarity index (\%) for the $16 \mathrm{~S}$ rRNA libraries between different grazing treatments.

\begin{tabular}{lccr}
\hline & LG $(\%)$ & MG $(\%)$ & HG $(\%)$ \\
\hline CK & 21 & 21 & 17 \\
LG & & 28 & 15 \\
MG & & & 25 \\
\hline
\end{tabular}

Treatments: control without grazing (CK), light grazing (LG), moderate grazing (MG), and heavy grazing (HG).

\section{DISCUSSION}

\section{Bacterial diversity with grazing}

Soil disturbances caused by natural or human activities have a direct impact on ecosystem properties and function, such as physical and chemical complexity and nutrient cycling (Greenberg and McNab, 1998; Ulanova, 2000; Wright and Coleman, 2002). Soil processes are greatly influenced by bacterial community structure, activity, and stability (McCaig et al., 2001; Coleman and Whitman, 2005). The effects of grazing on grassland soil bacterial diversity have not been well studied (Kennedy, 1999), therefore it is essential to investigate the microbial diversity of different grazing intensities on the grassland soil. This could provide a better understand of soil quality and the grassland ecosystem related to grazing disturbance.

Grazing has important potential consequences for patterns of microbial biodiversity in grassland soils and there is great concern over how this may impact ecosystem productivity and function. It has been shown that extensively grazed sites have lower plant biomass and diversity (Howe et al., 2002). Moderate grazing has increased bacterial diversity significantly compared to 
conditions of no grazing and heavy grazing, but trends in the response of soil properties (organic carbon, organic nitrogen, and ammonium) to grazing intensity do not show the same pattern (Zhou et al., 2010). Jangid et al. (2008) found that pastures with the highest bacterial diversity could be characterized as having an intermediate degree of intervention compared to low intervention in forest and high intervention in cropland. In the study, the change in bacterial diversity along a disturbance gradient was consistent with changes in soil carbon and nitrogen levels, which also showed a unimodal response. Diversity of functions appeared to follow no clear pattern in response to different grazing intensities, suggesting that the bacterial diversity of both ungrazed and moderately grazed sites were the largest, while lightly grazed sites had the lowest diversity. Again, this pattern was different for soil organic carbon and nitrogen levels (Liu et al., 2011). Using high throughput metagenomics technology, Yang et al. (2013) found that the genetic diversity of functional genes and soil properties all decreased under livestock grazing. According to the results of our study, the Shannon index, Simpson index and Margalef richness all increased linearly with grazing intensity. Such disturbances can clearly influence bacterial community-level diversity so understanding disturbance effects on species and functional diversity is fundamental to conservation planning (Connell, 1978; Sousa, 2001). Together, the studies described above illustrate that the relationship between disturbance and microbial biodiversity is complex. The research of Zhou et al. (2010) and Jangid et al. (2008) support the IDH, but more bacterial diversity did not coincide with habitat stability. The IDH, originally offered as an explanation for species diversity in plants and sessile animals (Connell, 1978), predicts that an intermediate frequency or intensity of disturbance will maximize diversity. However, other evidence suggests that there are other forms of the relationship: negative (Yang et al., 2013), positive, or even no significant relationship (Hughes et al., 2007), and that geographic location influences the diversitydisturbance response (Death and Barquín, 2012). Our research demonstrated a positive relationship between disturbance and bacterial diversity.

On the other hand, microbial diversity and ecosystem stability also have a close and controversial relationship. Previous studies showed that species richness and evenness can improve the resilience of large biological communities (Allison, 2004; Downing and Leibold, 2010; Van Ruijven and Berendse, 2010), but other studies showed that the effects of species diversity on ecosystem restoring force is not clear (Griffiths et al., 2000; Wittebolle et al., 2009; van Elsas et al., 2012). Zhou et al. (2010) suggested that moderate grazing is the most suitable management practice in the Inner Mongolian steppe according to the diversity-stability hypothesis (MacArthur, 1955), which states that higher species diversity results in greater ecological stability. However, this relationship can also take other shapes, as proposed by the redundancy hypothesis (Lawton and Brown, 1993), rivet hypothesis (Ehrlich and Ehrlich, 1982) and idiosyncratic hypothesis (Lawton and Brown, 1993). In our study, the increase in diversity observed with a rise in grazing intensity was different from previous studies. Since the measure of "degree of disturbance" is qualitative rather than quantitative, it is difficult to determine whether the degree of disturbance in each study is consistent with the degrees that are intended in the various hypotheses. It therefore makes it difficult to judge what hypothesis is supported by our results. Thus, determination of the "ideal" grazing intensity, to minimize ecological disturbance, requires further research that also considers other indices in the analysis of diversity responses.

\section{Changes in bacterial community structure with grazing}

Our results showed that the composition and structure of soil bacterial communities changed with grazing intensity (Tables 2 and 3). This observation is consistent with previous studies 
that have addressed grazing effects on microbial community structure, most of which concerned influences at the species level (Dowd et al., 2008; da C Jesus et al., 2009). Changes in microbial community structure were largely observed as shifts in the relative proportions of the species present. Two bacterial species were dominant in all treatment sites (Acidobacteria and Proteobacteria) and accounted for a large proportion of each community with small differences among treatments. These two species expanded to occupy large portions of the soil habitat under disturbances and appear to have adapted well to grazing conditions. Another six bacterial species (Bacteroidetes, Actinobacteria, Gemmatimonadetes, Nitrospirae, Planctomvcetes and Verrucomicrobia) were also present in all sites, though in significantly differing proportions. It may be that the ability of those species to adapt is relatively weak. A further seven species of bacteria were also distributed differently among treatments (OD1, TM7, Firmicutes, Cyanobacteria, Armatimnadetes, Chlorflexi, and unclassified bacteria). Notably, five species appeared only in the sites that experienced no grazing. This showed that the grazing disturbance affected not only the abundance of each bacterial species, but also determined which species were present in the bacterial community.

In general, it remains to be determined whether microbial diversity alone can provide a reasonable index of ecosystem stability. Given the complex relationship between disturbance, diversity and ecosystem function, a combination of information about microbial diversity, microbial community structure, microbial biomass and soil chemical properties should be used to identify the most suitable management practices for grassland ecosystems.

\section{Conflicts of interest}

The authors declare no conflict of interest.

\section{ACKNOWLEDGMENTS}

Research supported by the National Basic Research Program of China (\#2014CB138702). We are grateful to Dr. Hui Song, Xinjiang Chen and Zhixin Zhang for their assistance.

\section{Supplementary material}

\section{REFERENCES}

Allison G (2004). The influence of species diversity and stress intensity on community resistance and resilience. Ecol. Monogr. 74: 117-134.

Belay-Tedla A, Zhou X, Su B, Wan S, et al. (2009). Labile, recalcitrant, and microbial carbon and nitrogen pools of a tallgrass prairie soil in the US Great Plains subjected to experimental warming and clipping. Soil Biol. Biochem. 41: 110-116.

Bilotta G, Brazier R and Haygarth P (2007). The impacts of grazing animals on the quality of soils, vegetation, and surface waters in intensively managed grasslands. Adv. Agron. 94: 237-280.

Coleman DC and Whitman WB (2005). Linking species richness, biodiversity an ecosystem function in soil systems. Pedobiologia 49: 479-497.

Connell JH (1978). Diversity in tropical rain forests and coral reefs. Article in: Foundation of Tropical Forest Biology. Pages 259-279.

da C Jesus E, Marsh TL, Tiedje JM and de S Moreira FM (2009). Changes in land use alter the structure of bacterial communities in western Amazon soils. ISME J. 3: 1004-1011.

Death RG and Barquín J (2012). Geographic location alters the diversity-disturbance response. Freshwater Sci. 31: 636-646.

Dowd SE, Callaway TR, Wolcott RD, Sun Y, et al. (2008). Evaluation of the bacterial diversity in the feces of cattle using 16S rDNA bacterial tag-encoded FLX amplicon pyrosequencing (bTEFAP). BMC Microbiol. 8: 125. 
Downing AL and Leibold MA (2010). Species richness facilitates ecosystem resilience in aquatic food webs. Freshwater Biol. 55: 2123-2137.

Ehrlich PR and Ehrlich AH (1982). Extinction: the causes and consequences of the disappearance of species. Published by Random House, Gollancz, London.

Greenberg $\mathrm{CH}$ and $\mathrm{McNab}$ WH (1998). Forest disturbance in hurricane-related downbursts in the Appalachian mountains of North Carolina. Forest Ecol. Manag. 104: 179-191.

Griffiths B, Ritz K, Bardgett RD, Cook R, et al. (2000). Ecosystem response of pasture soil communities to fumigation-induced microbial diversity reductions: an examination of the biodiversity-ecosystem function relationship. Oikos 90: $279-294$.

Grigulis K, Lavorel S, Krainer U, Legay N, et al. (2013). Relative contributions of plant traits and soil microbial properties to mountain grassland ecosystem services. J. Ecol. 101: 47-57.

Howe H, Brown J and Zorn-Arnold B (2002). A rodent plague on prairie diversity. Ecol. Lett. 5: 30-36.

Hughes AR, Byrnes JE, Kimbro DL and Stachowicz JJ (2007). Reciprocal relationships and potential feedbacks between biodiversity and disturbance. Ecol. Lett. 10: 849-864.

Hughes A (2012). Disturbance and diversity: an ecological chicken and egg problem. Nat. Ed. Knowl. 3: 48.

Jangid K, Williams MA, Franzluebbers AJ, Sanderlin JS, et al. (2008). Relative impacts of land-use, management intensity and fertilization upon soil microbial community structure in agricultural systems. Soil Biol. Biochem. 40: 2843-2853.

Johnsen K, Jacobsen CS, Torsvik V and Sørensen J (2001). Pesticide effects on bacterial diversity in agricultural soils-a review. Biol. Fert. Soils 33: 443-453.

Kennedy A (1999). Bacterial diversity in agroecosystems. Agr. Ecosyst. Environ. 74: 65-76.

Kozdroj J and van Elsas JD (2001). Structural diversity of microorganisms in chemically perturbed soil assessed by molecular and cytochemical approaches. J. Microbiol. Meth. 43: 197-212.

Lawton J and Brown V (1993). Biodiversity and Ecosystem Function. Published In: Biodiversity and Ecosystem Function. Springer, Berlin, pages 255-270.

Liu N, Zhang Y, Chang S, Kan H, et al. (2012). Impact of grazing on soil carbon and microbial biomass in typical steppe and desert steppe of Inner Mongolia. PLoS One 7: e36434.

Liu T, Nan Z and Hou F (2011). Culturable autotrophic ammonia-oxidizing bacteria population and nitrification potential in a sheep grazing intensity gradient in a grassland on the Loess Plateau of Northwest China. Can. J. Soil Sci. 91: 925-934.

Lynch J, Benedetti A, Insam H, Nuti M, et al. (2004). Microbial diversity in soil: ecological theories, the contribution of molecular techniques and the impact of transgenic plants and transgenic microorganisms. Biol. Fert. Soils 40: 363-385.

MacArthur R (1955). Fluctuations of animal populations and a measure of community stability. Ecology 36: 533-536.

Mackey RL and Currie DJ (2001). The diversity-disturbance relationship: is it generally strong and peaked? Ecology 82: $3479-3492$

McCaig AE, Glover LA and Prosser JI (2001). Numerical analysis of grassland bacterial community structure under different land management regimens by using $16 \mathrm{~S}$ ribosomal DNA sequence data and denaturing gradient gel electrophoresis banding patterns. App. Environ. Microbiol. 67: 4554-4559.

Oates LG, Balser TC and Jackson RD (2012). Subhumid pasture soil microbial communities affected by presence of grazing, but not grazing management. Appl. Soil Ecol. 59: 20-28.

Schwartz M, Brigham C, Hoeksema J, Lyons K, et al. (2000). Linking biodiversity to ecosystem function: implications for conservation ecology. Oecologia 122: 297-305.

Sousa W (2001). Natural disturbance and the dynamics of marine benthic communities. In Bertness MD, Gaines SD, Hay M, (eds). Marine Community Ecol. Sinauer, Sunderland, Massachusetts, USA.

Stackebrandt E and Goebel B (1994). Taxonomic note: a place for DNA-DNA reassociation and 16S rRNA sequence analysis in the present species definition in bacteriology. Int. J. Syst. Bacteriol. 44: 846-849.

Sugden AM (2000). Diversity \& Ecosystem Resilience. Science 290: 233-235.

Ulanova NG (2000). The effects of windthrow on forests at different spatial scales: a review. Forest Ecol. Manag. 135: 155-167.

van der Heijden MG, Klironomos JN, Ursic M, Moutoglis P, et al. (1998). Mycorrhizal fungal diversity determines plant biodiversity, ecosystem variability and productivity. Nature 396: 69-72.

van Elsas JD, Chiurazzi M, Mallon CA, Elhottovā D, et al. (2012). Microbial diversity determines the invasion of soil by a bacterial pathogen. Proc. Natl. Acad. Sci. U.S.A. 109: 1159-1164.

Van Ruijven J and Berendse F (2010). Diversity enhances community recovery, but not resistance, after drought. J. Ecol. 98: 81-86.

Wittebolle L, Marzorati M, Clement L, Balloi A, et al. (2009). Initial community evenness favours functionality under selective stress. Nature 458: 623-626.

Wright C and Coleman D (2002). Responses of soil microbial biomass, nematode trophic groups, N-mineralization, and litter decomposition to disturbance events in the southern Appalachians. Soil Biol. Biochem. 34: 13-25.

Yang Y, Wu L, Lin Q, Yuan M, et al. (2013). Responses of the functional structure of soil microbial community to livestock grazing in the Tibetan alpine grassland. Glob. Change Biol. 19: 637-648.

Zhou X, Wang J, Hao Y and Wang Y (2010). Intermediate grazing intensities by sheep increase soil bacterial diversities in an Inner Mongolian steppe. Biol. Fert. Soils 46: 817-824. 